\title{
frabalhonecessário
}

issn: 1808 - 799x

ano 8 - número 11 - 2010

\section{ARTIGO \\ A SOFISTICAÇÃO DA APRENDIZAGEM SIMPLES: as experiências do PNQ e da inserção produtiva nos CRAS ${ }^{1}$}

\section{Simone Lessa - elizasimone@gmail.com}

Resumo: O presente artigo apresenta reflexões sobre a formação inicial e continuada dos trabalhadores que ocuparão as tarefas menos complexas do mundo do trabalho. Aqui analisamos a execução da qualificação profissional no Brasil contemporâneo, viabilizada através Ministério do Trabalho e Emprego, pela via do Plano Nacional de Qualificação (PNQ). Nas margens desta experiência, apresentamos ainda, aprendizagem que objetiva a geração de renda, denominada de inserção produtiva, executada nos Centros de Referência da Assistência Social (CRAS), vinculados ao Ministério do Desenvolvimento Social e do Combate à Fome. Esta aprendizagem está dirigida aos usuários da política de Assistência Social, em especial, aos usuários do Programa Bolsa Família (PBF). Nosso lócus de estudo é o Estado do Rio de Janeiro, com ênfase na região da Baixada Fluminense.

Palavras chave: Educação, trabalho, qualificação de trabalhadores, assistência social

\section{1- INTRODUÇÂO}

Nossa reflexão trata da formação de trabalhadores que atuam nos postos de trabalho mais simples e de frágil proteção social. Estamos falando da força de trabalho desempregada e auto denominada autônoma, que busca nos processos de qualificação e requalificação profissional, novas possibilidades de acesso, permanência no mercado de trabalho formal, ou ainda, possibilidade de geração de renda.

\footnotetext{
1 Simone Eliza do Carmo Lessa, Assistente Social do Instituto de Aplicação Fernando Rodrigues da Silveira, CAp/UERJ, Mestre em Educação (UFF), Doutora em Serviço Social (UFRJ).
} 


\title{
frrabahonecessário
}

\author{
issn: $1808-799 x$ \\ ano 8 - número 11 - 2010
}

Para compreensão da materialidade do nosso objeto - a qualificação de trabalhadores - destacamos a força da idéia da formação na sociedade contemporânea, em especial no atual contexto de crise do capital. O século XXI nasce com uma aparente marca da democratização da informação, da tecnologia e da educação. Os avanços tecnológicos são inegáveis e tornam possível acessar de casa bibliotecas de grandes universidades, salas de museus, ouvir sinfonias, divulgar informações em segundos, conversar em tempo real com conhecidos e desconhecidos fisicamente distanciados, fortalecendo a ilusão de que os extremos econômicos e sociais foram aproximados. De fato, as redes que conectam virtualmente tecnologias diversas e as pessoas por trás das mesmas, fazem parte da vida das camadas médias urbanas e parecem construir relações de novo tipo, criando a falsa noção de que o conhecimento produzido socialmente e dominado historicamente por grupos dotados de grande poder econômico e social igreja, universidade, burguesia - está agora disponível para todos, superando barreiras de todos os tipos.

Ledo engano potencializado ao extremo no plano fenomênico. No plano aparente, a idéia do fim das tensões de classe e da existência de um novo tipo de poder, desvinculado do capital e transclassista, materializado na informação e na formação, ascende. Nesta conjuntura, o conhecimento - e mais do que isso - a educação em seus diversos processos, incluindo aqueles relativos à formação profissional - ressurgem revalorizados, passando a ser denominados de "novo capital" ou "capital social". Trata-se da falácia da sociedade do conhecimento, que tem suas bases na Teoria do Capital Humano ${ }^{2}$ resgatada por autores como Toffler (1980) e tão bem criticada por Frigotto (1995 e 1998) e Gentili (1994), entre outros.

\footnotetext{
${ }^{2} \mathrm{Na}$ década de 1950, momento em que os debates sobre o desenvolvimento e o subdesenvolvimento eram intensos, o economista americano Theodore Schultz cunhou o conceito de Capital Humano (FRIGOTTO, 1998). Segundo este, as diferenças econômicas entre os países do centro e periferia podem ser explicadas pelas diferenças de nível educacional entre estes. Da mesma forma, trazendo para o âmbito mais individual, as diferenças econômicas e sociais entre os indivíduos poderiam ser creditadas ao investimento que estes fizeram em sua própria educação. Graças a esta teoria, Shultz ganhou o Prêmio Nobel de Economia. Isso, porém, somente ocorreu em 1979, no avanço de uma então nova crise do capital, ocasião em que esta teoria teve todos os ingredientes para florescer. Desde então, a Teoria do Capital Humano vem germinando, criando novas folhagens, sem modificar suas raízes.
} 


\title{
frrabahonecessário
}

\author{
issn: $1808-799 x$ \\ ano 8 - número 11 - 2010
}

Dentro desta visão que coloca a educação como elemento central (e quase exclusivo) de superação da desigualdade - que aqui denominaremos de centralidade educacional - destacamos as idéias do empreendedorismo e do produtivismo da formação, da educação por competências e para a vida produtiva, todas estas limitadoras da formação humana ${ }^{3}$. Todos estes conceitos foram analisados e criticados por autores como Frigotto (1993 e 1995), Ramos (2001), Rummert (2000) e Fidalgo (2007), por sua fragilidade teórica e submissão a uma visão educativa e de mundo em que o escamoteamento da exploração do trabalho é a tônica.

Segundo a lógica da sociedade do conhecimento é preciso perseguir e conquistar individualmente este capital, já que ele é o instrumento fundamental de ascensão social na contemporaneidade. Neste sentido, a busca pela qualificação permanente para a conquista de mais "capital" e de melhor lugar na sociedade, é intensamente estimulada e valorizada. As faces competitiva, individualizante e mercantil do capitalismo, acirradas pela atual crise do capital, transformam a educação e o conhecimento também em objetos mercantilizados. Os resultados do investimento educacional (positivos ou negativos) são também individualizados, chegando à máxima de que o desemprego é resultado da falta de qualificação do trabalhador, cantilena esta que nos assola cotidianamente. Nesta mesma linha de idealização e maximização das potencialidades da política educacional, encontramos o pensamento denominado de Educacionismo ${ }^{4}$, que credita exclusivamente a esta política, as possibilidades de construção de justiça social.

Como expressão cotidiana deste processo, destacamos as recomendações empresariais em torno da permanente qualificação da força de trabalho, na intenção de torná-la competitiva frente à dinâmica econômica internacional, como as propaladas pela

\footnotetext{
${ }^{3}$ Formação que busca a complexidade e a integralidade do ser humano, oferecendo-lhe instrumentos para a leitura do mundo, intervenção sobre o mesmo, exercício de uma atividade produtiva e domínio dos princípios científicos contidos na mesma (SAVIANI, 1994). Incluímos: formação capaz de permitir que o homem veja e compreenda o mundo para além dele mesmo.

${ }^{4} \mathrm{O}$ professor Christóvão Buarque da UnB argumenta que o educacionismo é uma perspectiva teórica que coloca as ações do campo educacional como atividade central de transformação do mundo contemporâneo. Para este autor, entre outros que Ihe são afiliados, a constituição de uma rede escolar pública, para todos, seria instrumento capaz de transformar e superar as desigualdades sociais do país.
} 


\section{frrabahonecessário}

CNI (2007). Nesta ótica a formação é transformada em instrumento para prover produtividade e fica resumida ao viés economicista.

Destacado que o produtivismo limita a formação à execução de uma dada tarefa no mundo do trabalho, queremos argumentar que existe uma "novidade" neste processo. O Brasil é um país que realizou sua industrialização sem o suporte da escola (CUNHA, 1995). Os trabalhadores dos campos mais simples em termos ocupacionais ficavam relegados ao aprendizado de suas tarefas nos próprios ambientes de trabalho e aprendiam fazendo, sem suporte educacional formal. Esta conduta vem mudando e as prescrições quanto à qualificação permanente e a valorização do capital-conhecimento têm chegado aos trabalhadores das áreas mais simples, historicamente relegados ao aprendizado na realização da tarefa produtiva em si.

Estamos falando de cursos de curtíssima duração, voltados para ocupações no setor de serviços, especialmente - atividades administrativas simples, informática básica, cozinha, reparos domésticos (campos de destaque na aprendizagem profissional, segundo a PNAD, 2007, divulgada amplamente nos meios de comunicação ${ }^{5}$ ). Falamos também de cursos que objetivam preparar para o trabalho informal, oferecendo fundamentos para o trabalhador "empreender", ou seja, para organizar um pequeno negócio, em geral relacionado ao comércio ambulante. Estes cursos são oferecidos por instituições privadas, em sua maioria, mas no primeiro grupo citado, também por instituições públicas, como as escolas técnicas estaduais.

Nosso argumento é de que as prescrições para qualificação permanente estão chegando aos trabalhadores das ocupações mais simples, aqueles que realizam as tarefas menos complexas, repetitivas, insalubres, menos protegidas e destituídas de status, visto que detêm característica bastante manual. Buscando compreender este processo, discutimos a qualificação de trabalhadores realizada através do Plano Nacional de Qualificação (PNQ), vinculado ao Sistema Público de Emprego (SPE) e estruturado pelo Ministério do Trabalho e Emprego (MTE) no governo de Lula da Silva.

\footnotetext{
${ }^{5}$ Aqui citamos material divulgado pelo Observatório Jovem, mas jornais como O Globo, Jornal do Brasil e Folha de São Paulo noticiaram estes mesmos dados sobre a PNAD 2007 e a Educação profissional.
} 


\title{
trabalhonecessário
}

\author{
issn: $1808-799 x$ \\ ano 8 - número 11 - 2010
}

Nas margens desta experiência, em situação ainda mais frágil, analisamos ainda um outro modelo de aprendizagem para o trabalho, denominado de inserção produtiva, viabilizado através dos CRAS (Centros de Referência da Assistência Social), estruturados a partir do SUAS (Sistema Único da Assistência Social), vinculados ao Ministério do Desenvolvimento Social e Combate à Fome (MDS). Atentemos para o fato de que, apesar de tratarmos de uma política de formação, não fizemos qualquer menção ao Ministério da Educação, MEC, o que denota que a aprendizagem de trabalhadores tal como está estruturada, orbita marginalmente a educação oficial.

A opção por este objeto nasce de sua relevância social, da nossa experiência profissional com jovens trabalhadores, bem como da certeza de que, analisando o PNQ e a inserção produtiva dos CRAS, podemos conhecer elementos importantes da formação de trabalhadores das periferias econômicas, sua concretização e sofisticação - ainda que esta não rompa com a precariedade da experiência. Também entendemos que nestas estruturas estão contidos os contornos e as tensões da relação entre o capital e trabalho e entre projetos de formação partidos pela dualidade estrutural ${ }^{6}$ - para os trabalhadores formação simples e atitudinal e para a burguesia formação complexa e científica.

Para fazermos tal argumentação, analisamos as qualificações profissionais iniciais de trabalhadores, por meio dos dados do PNQ, disponibilizados nos Anuários de Qualificação Social e Profissional do Departamento Intersindical de Estatística e Estudos Socioeconômicos (DIEESE) e do Ministério do Trabalho e Renda (2006; 2007; 2008), dos documentos de avaliação do Plano produzidos pela Unitrabalho ${ }^{7}$ e, de modo especial, por intermédio dos dados coletados nas Secretarias de Trabalho e Renda, tanto do estado

\footnotetext{
${ }^{6}$ A sociedade capitalista é marcada pela cisão entre os detentores dos meios de produção e aqueles que detêm, somente, sua a força de trabalho. Este quadro de desigualdade se expressa em condições desiguais de existência e as políticas educacionais são um dos espaços de sua evidência. Como concretização desta dualidade, citamos a formação a que tem acesso a elite e aquela a que têm acesso os trabalhadores. Em uma sociedade complexa como a capitalista contemporânea, esta dualidade é escalonada, formando segmentos de trabalhadores de aprendizados distintos: quanto mais periférico o seu lugar na produção, mais simplificada e periférica a sua formação.

${ }^{7}$ A Rede Unitrabalho é composta por 92 universidades e instituições de ensino superior, no Brasil, que desenvolvem projetos, pesquisas e capacitações sobre o trabalho. Esta rede é responsável pela avaliação do Plano Nacional de Qualificação. Nossa análise foi elaborada, principalmente, sobre os documentos "Políticas Públicas de Qualificação: desafios atuais" e o "Novo momento para as comissões de emprego no Brasil ?", citados em nossa bibliografia.
} 


\title{
frabalhonecessário
}

\author{
issn: $1808-799 x$ \\ ano 8 - número 11 - 2010
}

quanto do município do Rio de Janeiro, referentes ao intervalo de 2005 a 2008. Também, levantamos e analisamos o perfil da inserção produtiva realizada nos CRAS, oferecida em

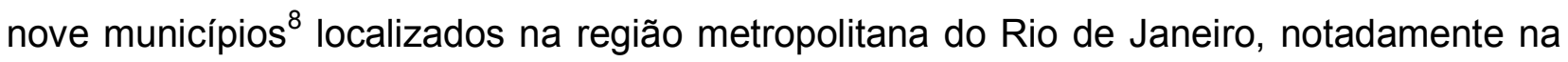
Baixada Fluminense ${ }^{9}$. A esse material de análise, somam-se dados trabalhados e divulgados por instituições como o Instituto Brasileiro de Geografia e Estatística (IBGE), o Instituto de Pesquisa Econômica Aplicada (IPEA) e o Ministério da Educação (MEC), como fontes principais de consulta.

Ademais, utilizamos levantamento próprio, realizado durante oito meses, sobre as notícias diárias quanto à aprendizagem profissional, no Brasil, com foco especial na região Sudeste e, mais especificamente, no estado do Rio de Janeiro. Tais informações foram divulgadas nos principais veículos de comunicação, via internet, e chegaram diariamente até nós, através de ferramenta de informática de busca de conteúdos a partir de palavraschave. Com base neste levantamento, tivemos acesso às principais notícias/informes dos ministérios, divulgação de cursos e reportagens contemporâneas sobre a qualificação inicial de trabalhadores via PNQ, bem como sobre as aprendizagens realizadas nos CRAS. Através destes, pudemos encontrar elementos para analisar características da Educação Profissional inicial de trabalhadores, suas formas de divulgação e características. Tais informações foram fundamentais para melhor compreensão do nosso objeto, e ousamos dizer que, sem esse suporte, nossa pesquisa ficaria muito mais restrita.

${ }^{8}$ Decidimos por não identificar os municípios analisados, uma vez que isso poderia revelar quem foram os profissionais que nos receberam. Ressaltamos que as equipes que executam a política de Assistência Social hoje (na Baixada e nacionalmente), em sua ampla maioria, possuem vínculos instáveis de trabalho e muita precariedade em seu cotidiano de exercício profissional. Apesar da disponibilidade em falar da sua realidade de trabalho, o temor pelas conseqüências deste ato era uma constante — o que nos parecia bastante real, especialmente no período de transição eleitoral no qual a maior parte da pesquisa foi realizada. Destacamos, ainda, que essa amostragem foi baseada na disponibilidade dos profissionais e gestores, mas é bastante representativa, visto que chegamos aos dados de nove cidades, em um território composto por catorze municípios, o que nos dá uma marca de $64 \%$ do total.

9 Também pesquisamos dados referentes aos CRAS, do município do Rio de Janeiro (RJ), mas estes foram descartados em nossa análise, pelo tratamento específico dessa experiência na capital. Melhor explicitando, no RJ, a inserção produtiva na gestão Cesar Maia é uma ação articulada à Escola Carioca de Empreendedorismo e não está voltada para todos os usuários dos CRAS, mas somente para aqueles que apresentem perfil empreendedor, o que nos pareceu um critério bastante subjetivo. Por esta particularidade, descartamos estes dados.

TrabalhoNecessário - www.uff.br/trabalhonecessario; Ano 8, № 11/2010. 


\section{frrabahonecessário}

issn: 1808 - 799x

ano 8 - número 11 - 2010

\section{2- CAPITALISMO E FORMAÇÃO:}

O capitalismo passa por mais uma de suas crises cíclicas. A atual tem assumido graves feições e sua fragilização parece distante. Sua origem guarda relação com o descompasso entre os processos de acumulação e os de consumo como aspecto mais geral e tem como causa mais imediata, conforme Gonçalves (2008), a amplíssima insolvência iniciada no sistema de hipotecas imobiliárias americanas. Os reflexos da crise são visíveis: governos estão mobilizados para reunir recursos públicos, ou segundo o jargão econômico, oferecer liquidez ao capital, na intenção de salvaguardá-lo. Como este objetivo, instituições financeiras privadas têm sido estatizadas e apoiadas materialmente de modo oficial, tanto no capitalismo central como no periférico. Tal situação não deve ser considerada inédita uma vez que a transferência de recursos públicos para o setor privado é um elemento de sustentação do padrão capitalista de acumulação.

A crise atual deve ser analisada especialmente por sua extensão mundial, pela rapidez com que providências no sentido de seu enfrentamento foram tomadas e pela junção de pensamentos diversos ,na justificativa da ação estatal para aplacá-la - da ultradireita à pseudo-esquerda. A crise revela seus reflexos no mundo do trabalho, aprofundando aspectos inerentes ao capitalismo, como a desigualdade e a desproteção de significativas faixas de trabalhadores. Neste sentido, crescem o desemprego e a proteção ao capital e decrescem os níveis de renda dos trabalhadores e a estrutura da seguridade, mas neste campo, as respostas do poder público não são tão rápidas. Certamente, é da redução dos custos relativos aos salários e da proteção social, além da maximização da exploração, que sairá a base financeira de proteção do capital.

Este contexto repercute no campo das idéias: a crise precisa ser entendida como um elemento natural da ordem econômica, plenamente superável se todos (leia-se, os trabalhadores) cooperarem. Fazendo a aproximação com nosso objeto, entendemos que diante da crise atual, está havendo o aprofundamento da valorização da qualificação 


\title{
frrabalhonecessário
}

\author{
issn: $1808-799 x$ \\ ano 8 - número 11 - 2010
}

permanente para a vida produtiva e da falácia de que o desemprego é resultado da falta de formação e de empenho individual, o que tem repercussões nas políticas educacionais e de formação de trabalhadores. Avaliamos, portanto, que no atual contexto, as ideologias da sociedade do conhecimento e da centralidade educacional serão ainda mais valorizadas, enquanto que os processos de formação humana em sentido amplo, serão duramente atingidos.

Passemos a indicar reflexos deste contexto sobre a formação de trabalhadores. Primeiramente vale lembrar que o capital, ao longo de sua história, organiza-se no sentido de assegurar sua reprodução, rebaixando os custos com da força de trabalho - esta que é a mais eficaz estratégia para fazer crescer a acumulação de capital (MARX, 1985). Por esta razão, na relação capital/trabalho a negação, a restrição e/ou a conquista de direitos compõem uma página em permanente construção e tensão, gerando avanços e retrocessos na história do capitalismo. Em sua face atual, o resultado desta tensão atende pelo nome de neoliberalismo, que se faz presente na gestão da economia, com reflexos desta na vida social. As práticas neoliberais potencializam os ataques aos direitos dos trabalhadores $^{10}$ com o aval do Estado (SOARES, 2002). Na realidade brasileira de capitalismo "hipertardio" (ANTUNES, 2006) o projeto de maximização dos lucros do capital teve demolidora ação sobre o frágil Estado de Bem Estar.

Neste sentido, novas políticas gerenciais são instituídas na intenção de elevar patamares de produtividade e fazer crescer a extração de mais-valia. Estamos falando da importação de orientações para a organização da produção e para a gestão da mão-deobra, em especial dos americanos e japoneses - tais como as células, a produção horizontalizada, o sistema "just in time", os "programas de qualidade de vida", os círculos de produção - que surgem aliados às terceirizações e à precarização do trabalho ${ }^{11}$. A

\footnotetext{
${ }^{10}$ Analisando documento do Banco Mundial, Borón (2003) destaca a orientação deste organismo de financiamento para a América Latina na década de 1990: abandonar o chamado intervencionismo estatal, pelo supostamente mais eficiente, modelo de liberalização centrado no mercado.

${ }^{11}$ Lembramos de Martins (2001) que em seu estudo aponta que os processo de reestruturação produtiva atingiram muito mais a organização da mão-de-obra do que o aparato produtivo, propriamente dito. Nosso modelo reestruturador periférico atinge aos trabalhadores, barateando ainda mais os custos da produção, mas não chega a transformar significativamente o parque industrial, pelos custos que esta prática teria.
} 


\section{frrabahonecessário}

intenção é conquistar a adesão dos trabalhadores a estas ações que prometem tornar os ambientes mais eficientes, produtivos, menos áridos e, por que não dizer, mais "afetivo". Gurgel (2003) sinaliza o caráter ideológico destas propostas desvendando que sua intenção, além do aumento da produtividade, é a captura da subjetividade do trabalhador e o escamoteamento da luta de classes. O caráter predatório do capital sobre a força de trabalho, tanto na materialidade quanto na subjetividade fica evidente.

As relações de trabalho, por sua vez, estão diretamente submetidas à constituição do modelo produtivo. Desta forma, os modelos de gestão de mão-de-obra acima identificados, tentarão moldar o trabalhador ideal para o atual padrão produtivo - disponível, produtivo, dotado de multi-habilitações, capaz de se auto-gerenciar e de tomar conta dos colegas, agressivo na competitividade e dócil para a exploração. Pela complexidade da tarefa, porém, outras instituições sociais, muito além do ambiente de trabalho, serão convocadas para agir neste sentido. Trata-se de tarefa formativa importante, de grande apelo ideológico, que precisa ser massificada para ter êxito. Estamos falando da escola, das instituições de formação de trabalhadores e da mídia. Através destas, o perfil de trabalhador produtivo e dócil precisa ser estimulado. Certamente, existem resistências dos trabalhadores a este processo, mas a força do mesmo na atual conjuntura é inegável.

Estamos em momento de ampliação do trabalho temporário, terceirizado e precário. Desprotegida, esta mão-de-obra sobrevive alternando informalidade e formalidade, com remunerações instáveis em atividades simples, que não exigem, de modo geral, qualificação prévia (POCHMMAN, 1998). Na periferia, diante da evidente diminuição do proletariado fabril, na outra face desta mesma moeda, cresceram o trabalho precário e a subproletarização (ANTUNES, 1995). A modernização dos campos centrais da produção se constrói a partir da precarização de outros (ALVES, 2000), organizando experiências de trabalho distintas, com maior e menor índice de proteção social. Estudo do IPEA realizado por Campos e Amorim (2007) revela que, neste marco, o setor de serviços tem crescido significativamente. Trata-se, de fato, de um campo de trabalho em expansão que tem 


\title{
frabahonecessário
}

\author{
issn: 1808 - 799x
}

ano 8 - número 11 - 2010

superado quantitativamente a indústria, inclusive a de transformação e extrativismo, tradicionalmente dotadas de grande potência e de absorção significativa de trabalhadores.

Observando nosso objeto de análise, não por acaso, a área de serviços é a que mais oferece qualificações no PNQ e que a inserção produtiva dos CRAS seja organizada sobre aprendizados que remeterão ao comércio informal e às habilidades para cuidar de pessoas. Por esta razão, os trabalhadores atuantes nos setores periféricos e aqueles que vivenciam a subproletarização, apesar de parecerem estar fora deste processo que valoriza a produtividade e o adestramento, não podem estar à parte das orientações gerenciais para a força de trabalho central. Muito ao contrário disso. Eles não estão livres dos ajustes feitos para os trabalhadores mais centrais da produção, tampouco das prescrições dos modelos gerenciais aqui citados.

As formas em que estas determinações chegam até os mesmos é que são distintas. Se a tendência à desproteção e à intensificação da precarização atinge a mão-de-obra mais protegida e central nos processos produtivos, aos que estão nas periferias, não é diferente. Se para os primeiros a ameaça está relacionada às demissões, terceirizações, maximização da exploração e da produtividade, exigência permanente de requalificação profissional; para os demais, dentro desta mesma lógica, as ameaças estão na ampliação das dificuldades de acesso à formalidade, nas exigências em torno da empregabilidade, na execução de tarefas cada vez mais precárias e simplificadas, na aceitação de condições precárias de trabalho, no estímulo às requalificações frágeis e permanentes. Vejamos que para ambas as condições — proletários e subproletários - a exigência da aprendizagem para o trabalho e a adequação de conduta aos códigos da produção se evidenciam. Tais exigências, porém, não se concretizam no acesso ao emprego, ficando apenas no campo da promessa integradora (GENTILI, 1995).

Depois de relacionarmos o modelo de produção à gerência das forças produtivas e sua tentativa de adequação do trabalhador as mesmas, é hora de uma análise mais detalhada do campo da formação. O capitalismo necessita e o neoliberalismo busca prover um tipo de formação submetida ao mercado e à flexibilidade, detentora de conhecimentos 


\title{
frrabahonecessário
}

\author{
issn: $1808-799 x$
}

ano 8 - número 11 - 2010

interessados (GRAMSCI, 1988), apartada da compreensão do mundo e limitada às necessidades de prover agilidade à produção que é revolucionada permanentemente.

Dando suporte ideológico a este processo, destacamos a valorização do papel do mercado nas relações sociais. Alçado ao status de poder central, o mercado supostamente, identifica indivíduos mais aptos ao trabalho, os que mais empreenderam em prol de sua própria educação, organizando relações focadas na competitividade, de modo a reduzir o processo educacional a uma relação individualizada, desprovida de complexidade. Neste sentido, os processos educacionais ficam limitados ao papel de dar suporte para acesso ao mercado, reduzidos a o que desqualifica sua dimensão crítica. Feita esta breve reflexão sobre a formação contemporânea como pano de fundo para compreensão do nosso objeto de estudo, passaremos a analisar as experiências do PNQ e da inserção produtiva.

\section{3- O PNQ E A INSERÇÃO PRODUTIVA COMO EXPERIÊNCIAS DE FORMAÇÃO DE} TRABALHADORES:

O Plano Nacional de Qualificação, PNQ, integrado ao Sistema Público de Emprego, ${ }^{12}$ é a segunda experiência de organização de política de formação de trabalhadores ${ }^{13}$ de caráter nacional. Está estruturado através de ações territoriais (no caso do PlanTeQ) e por demandas setoriais (PlanSeQ), estando voltado diretamente para a força de trabalho em exercício ou em busca de emprego, ou seja, para a PEA. Apesar deste aparente foco genérico, de fato, o Plano está voltado para trabalhadores que desenvolverão as atividades mais simples, o que pode ser comprovado pelas áreas dos aprendizados oferecidos, assim como pelo perfil dos usuários que chegam aos cursos, como pode ser verificado nos Anuários de Trabalhadores de 2005 a 2008.

12 O Sistema Público de Emprego, Trabalho e Renda é uma estrutura do Ministério do Trabalho que agrega ações diversas: seguro desemprego, recolocação no mercado de trabalho, qualificação profissional e combate ao trabalho escravo são algumas destas. Sua estruturação no Brasil é bastante recente (data da ditadura).

${ }^{13}$ A primeira experiência de um plano especificamente montado para esta finalidade foi o Planfor (Plano Nacional de Qualificação do Trabalhador) implementado nos dois governos FHC, no período de 1995 a 2002. Esta experiência foi concretizada através de formações aligeiradas, frágeis em conteúdos científicos, e voltadas para as necessidades do mercado 


\title{
frrabahonecessário
}

\author{
issn: $1808-799 x$ \\ ano 8 - número 11 - 2010
}

Analisando o documento que institui o PNQ (MTE, 2003-2007), encontramos um material gerado em condições históricas de novo tipo e é esta a primeira consideração sobre o Plano que pretendemos fazer. "Nunca na história deste país" é uma das célebres frases de Lula da Silva que traduzirá muito bem o que pretendemos dizer. Nunca na história deste país foi tão complexo analisar as ações governamentais. Isto porque a combinação, em condição de proposição e de mando, de atores políticos com trajetórias de ação distintas - grupos oriundos do PT, partido que apesar de ter passado por processo de transformação de sua visão de sociedade e de poder, possuía propostas avançadas no campo das políticas sociais, combinados aos grupos mais conservadores, que se perpetuam nos espaços públicos ao longo de décadas - tem gerado como fruto ações governamentais dotadas de continuísmo, sob a argumentação da inovação. resultado desta união, portanto, é uma junção de um quebra cabeças em que as peças se encaixam, apesar de não construírem uma mesma imagem. Este fato traduz a complexidade da sociedade brasileira contemporânea e expressa a incorporação de interesses diversos - articulados nos limites da subordinação aos interesses do capital no interior de um padrão de Estado possuidor de perfil complexo.

Isso posto, passemos a apresentar alguns breves dados sobre a efetivação do Plano. Iniciemos por sua abrangência. O PNQ pretende atingir a uma meta mínima de $20 \%$ da PEA ao final de sua execução. No entanto, apesar de seu caráter nacional e de significativa divulgação em torno de seu amplo papel, o PNQ tem atingido uma média anual de 100 mil trabalhadores brasileiros, nacionalmente, e este número está em queda. Lembremos que a taxa nacional de desocupação é da ordem de $10 \%$, o que se comparado aos atendimentos do Plano revelará seu caráter pontual e fragilíssimo frente ás demandas por formação. Podemos afirmar, portanto, que a abrangência desta ação tem sido pequena, ou em outras palavras, muito aquém do divulgado pelo governo.

Dentre os grupos de arrolados como prioritários, visto que são compreendidos como dotados de grande vulnerabilidade social ${ }^{14}$, encontramos as minorias étnicas -

14 Esta terminologia tem sido muito utilizada no campo das políticas sociais em tempos neoliberais, especialmente por organismos internacionais de financiamento. Os mais vulneráveis são analisados segundo territórios e necessidade. O termo traduz a meta da focalização de uma ação em um determinado público 


\title{
frrabahonecessário
}

\author{
issn: 1808 - 799x
}

ano 8 - número 11 - 2010

especialmente negros e indígenas - as mulheres, os jovens e indivíduos de baixa escolaridade, subempregados e desempregados. Vejamos como estas metas $\mathrm{t} \sim \mathrm{em}$ sido cumpridas. De fato, as mulheres representam o grupo mais atendido em termos quantitativos pelo $P N Q$, pois além do perfil dos cursos indicarem uma "feminização" das aprendizagens, o gênero feminino tem sido público prioritário de muitas políticas de recorte social contemporâneas. A justificativa dos planejadores para tanto, diz respeito à capacidade feminina de multiplicar a informação, bem como por sua centralidade nas famílias. Vale ressaltar que esta valorização é estimulada por organismos de financiamento com os quais os governos dialogam e estabelecem parcerias, tais como o Banco Mundial. Já sobre a questão étnica, ressaltamos que os auto-declarados negros e pardos representam uma média de $50 \%$ dos usuários do Plano, em nível nacional, denotando que não há uma absorção especial ou prioritária deste público em relação aos demais. Dentre os egressos, encontramos uma média de $38 \%$ de negros e pardos, o que está em consonância com os níveis de desistência dos cursos. Quanto aos jovens verificamos que uma média de $37 \%$ do total de usuários está na faixa entre 16 a 24 anos, nacionalmente, e que no Rio de Janeiro este número é de $35 \%$, o que demonstra que esta política não pode ser denominada como ação especifica de juventude.

Outro dado para destaque diz respeito à escolaridade. O PNQ (2003-2007) em sua normatização afirma que deve estar voltado para as populações mais vulneráveis economicamente. A escolaridade de seus usuários está localizada na faixa do Ensino Médio completo, quando os brasileiros são detentores de média de 7,4 anos de estudo. Ainda que não possamos fazer uma avaliação linear de que a conclusão do Ensino Médio está relacionada, necessariamente, a um maior poder aquisitivo, visto que existem outras variáveis que merecem ser consideradas neste sentido, entendemos que a média escolar do usuário do PNQ destoa do perfil do brasileiro e está em discordância com o seu objetivo de chegar às populações mais frágeis em termos de acesso à educação.

Sobre o perfil dos usuários vale ressaltar a predominância de trabalhadores autodenominados de "por conta própria" e desempregados. Sobre o assunto é preciso ressaltar

que apresenta maior demanda sócio-econômica. Este tipo de conduta está associado à exigência de condicionalidades e tende a caminhar no sentido inverso na universalização de direitos. 


\section{frabahonecessário}

issn: 1808 - 799x

ano 8 - número 11 - 2010

que a maior fonte de divulgação do PNQ é o Sistema Nacional de Emprego, SINE, para onde são encaminhados trabalhadores recém desempregados ou em busca de acesso ao emprego formal e não há como negar que este quadro influencia o perfil empregatício dos usuários. Sobre as características dos cursos destacamos seu aligeiramento (média de duração oficial é de 200 horas $^{15}$, mas encontramos registros de formações realizadas com cargas menores), sua marginalidade quanto à formação escolar, visto que todos os cursos funcionam em estrutura à parte da aprendizagem formal e a simplicidade de seus conteúdos. Também registramos que, além dos aprendizados relativos ao fazer profissional em si, encontramos outros, relacionados ao cooperativismo, à economiza solidária e ao empreendedorismo, os dois primeiros temas, de grande relevância nas ações do governo atual.

As entidades executoras que mais se destacam quantitativamente na efetivação do Plano são o Sistema "S" e as ONGs (no momento, em franca expansão na execução desta ação), ou seja, apesar de se constituir em um sistema público de aprendizagem, dotado de financiamento de mesmo tipo, o PNQ é efetivado pela iniciativa privada, tal qual a educação profissional brasileira (PNAD, 2007). O PNQ afirma-se, assim, em mais uma estratégia de transferência de recursos públicos para setores privados. Quanto aos recursos, verificamos que a qualificação de trabalhadores é a penúltima ação em investimento no Sistema Público de Emprego, demonstrando a pouca importância efetiva dada a esta política. Além disso, os custos dos cursos vêm crescendo, mas os recursos destinados sofrem significativa retração, o que certamente tem implicações na já comentada qualidade dos mesmos. Concretamente, o governo Lula da Silva ainda não destinou $1 \%$ dos recursos do SPE à qualificação de trabalhadores, apesar de toda a propaganda oficial a respeito.

Resumindo o quadro aqui brevemente traçado, afirmamos que o PNQ tem chegado aos trabalhadores dos grandes centros urbanos, dotados de escolaridade média, atuantes

\footnotetext{
${ }^{15}$ Duzentas horas aula é o mínimo de aprendizagem estabelecida pelo Ministério do Trabalho. Verificamos que nos últimos anos este quantitativo de horas tem subido, alcançando esta média inicial, mas ainda são comuns os cursos com duração menor do que a preconizada, em especial, fora das grandes cidades.
} 


\section{frrabahonecessário}

issn: 1808 - 799x

ano 8 - número 11 - 2010

nas áreas produtivas mais simples, desempregados ou informais, que acessam as qualificações através do SINE, na busca por uma (re)inserção no mercado de trabalho formal. O fato do acesso ao Plano acontecer a partir deste Sistema reduz a possibilidade de aproximação desta política dos 49,7\% (PNAD, 2007) de trabalhadores que atuam na informalidade no Brasil contemporâneo.

Em outras palavras, $\mathrm{OPNQ}$ tal qual está estruturado, deixa de fora os trabalhadores com perfis mais precarizados, de baixa escolaridade, que jamais tiveram um emprego formal, ou que o fizeram há muito tempo e deixaram de buscá-lo. Neste sentido, podemos citar nossa experiência profissional com jovens pobres em programas de formação para o trabalho. Através desta encontramos uma juventude que sequer tem tentado chegar ao emprego formal, uma vez que sua trajetória de vida é tão impregnada pela marca da destituição, da experiência de estar à margem da sociedade e de direitos, que a busca por um emprego formal parece ilusória e acaba por ser abandonada.

Tratando agora da inserção produtiva dos CRAS, podemos afirmar que encontramos uma formação ainda mais periférica e marginal do que o já precário aprendizado do PNQ. Para melhor conhecermos esta ação, vejamos a configuração contemporânea da assistência e a efetivação dos CRAS. A Política Nacional de Assistência Social (PNAS) aprovada em 2004 tem seus pilares contidos na LOAS (Lei Orgânica da Assistência Social, 8742/1993), traduzidos no SUAS (Sistema Único da Assistência Social). Os CRAS devem ser uma das corporificações deste processo. Tais centros são as unidades principais de execução da política nacional de Proteção Social Básica sendo detentores de base territorial segundo níveis de vulnerabilidade social da região. Executa serviços socioassistenciais, focados nos mais frágeis em termos sociais e econômicos, ou seja, na população que sofre com os reflexos mais graves da desigualdade: desemprego, emprego precário, falta de moradia, ou moradia precária, desinformação, adoecimento, violência, falta de acesso a outras políticas públicas, entre outros. 


\title{
frrabahonecessário
}

\author{
issn: $1808-799 x$ \\ ano 8 - número 11 - 2010
}

Também chamados pelo MDS (Ministério do Desenvolvimento Social e Combate à Fome) de Casa da Família, os CRAS têm a pobreza absoluta ${ }^{16}$ como foco da execução de suas políticas. Nestes espaços, segundo o MDS, devem ser prestados serviços como acolhimento, acompanhamento em serviços socioeducativos e de convivência, ações socioassistenciais, encaminhamentos para a rede de proteção social e para os demais serviços das outras políticas sociais, orientação e apoio na garantia dos seus direitos de cidadania e de convivência familiar e comunitária, acesso à programas de transferência de renda. Concretamente, os atendimentos centrais dizem respeito à atenção à pobreza, privação econômica, fragilização de vínculos familiares. Trata-se da tentativa de organizar uma nova operacionalização para uma política que tem como marcas históricas o assistencialismo, o atendimento precário, realizado por instituições filantrópicas de perfil privado, personalista, emergencial e amador, uma vez que voltado para as populações que atuam nas franjas precaríssimas da produção e que desconhecem direitos básicos. Devido a estas determinações, os limites a transpor não são poucos.

Da mesma forma que o $P N Q$, a inserção produtiva desenvolve-se junto ao público feminino, desta vez, mulheres chefes de família, usuárias da política de assistência, em especial do Programa Bolsa Família (PBF). Nos CRAS são oferecidas aprendizagem de tarefas simples, recortadas por conteúdos relativos à auto-estima e ao cooperativismo, com vistas à geração de renda, como estratégia de construção de autonomia para futuro desligamento desta política. Em uma de suas falas, o então Ministro do Desenvolvimento Social, Patrus Ananias, afirmou que a Política de Assistência Social deve ter "portas de saída" para evitar que os usuários entrem e permaneçam na condição de "assistidos" por

${ }^{16}$ A pobreza absoluta pode ser definida por critério de renda (indivíduos que vivem com menos de 1 dólar ao dia é um dos parâmetros utilizados pelo Banco Mundial, por exemplo), acrescida de aspectos que se somam a esta e são multidimensionais, tais como dificuldades de acesso aos serviços públicos, à moradia, ao transporte. As políticas de assistência social têm hoje melhores níveis de efetividade junto às populações mais pobres, mas ainda existem grupos empobrecidos que não conseguem chegar até estas. Dentre estes, além dos que estão cadastrados e aguardam efetivo acesso ao PBF, temos aqueles grupos que não reúnem condições de acessar este benefício. De um lado, as populações mais fragilizadas economicamente, que residem de modo itinerante, sem registro civil e longe das áreas urbanas, que sequer conseguem chegar aos CRAS. De outro, os trabalhadores pobres que possuem renda per capita familiar superior aos $\mathrm{R} \$ 137$ reais praticados pelo PBF. Estes grupos estão fora da política de assistência social. 


\title{
frrabahonecessário
}

\author{
issn: $1808-799 x$ \\ ano 8 - número 11 - 2010
}

muito tempo ${ }^{17}$. Este tipo de percepção revela uma noção equivocada dos direitos sociais e do público demandatário desta política. As mulheres vinculadas à Assistência Social, conforme revela o próprio MDS, são trabalhadoras e possuem renda proveniente do trabalho doméstico ou do comércio informal e buscam a inserção produtiva como complemento de renda e espaço de convivência.

As entidades promotoras desta aprendizagem são instituições assistenciais municipais, em geral ONGs, que já realizam ação semelhante em seus muros e estabelecem parcerias com os CRAS. Os professores são também chamados de oficineiros e atuam sob prisma informal. A média escolar dos usuários está situada nas séries finais do Ensino Fundamental e as aprendizagens mais comuns são as do campo do artesanato e estética (manicure e práticas simples de cabeleireiro) ${ }^{18}$.

O Ministério o Desenvolvimento Social e o Programa das Nações Unidas para o Desenvolvimento, PNUD, têm estimulado a organização de parcerias com instituições formais de educação para a realização das aprendizagens nos CRAS. No entanto, diante da ausência de destinação recursos específicos para este fim, raras foram as experiências estruturadas com algum tipo de suporte de instituições de ensino formal. Sendo assim, em meio à precariedade e ausência de recursos, o que se produz é uma aprendizagem empobrecida para os pobres, na expectativa de gerar acesso ao mercado de trabalho e à renda. Destituída de infra-estrutura material e humana, desarticulada de outras políticas de cunho educacional e do trabalho, completamente alijada do ensino formal, dotada de caráter imediatista, a inserção produtiva fica caracterizada por sua precariedade e pelo tom caricatural com que constrói a aprendizagem de trabalhadores. Trata-se de uma experiência ainda mais frágil do que aquela oferecida no $P N Q$, portanto.

\section{4- CONCLUSÃO: capitalismo em crise e qualificação profissional fetichizada}

\footnotetext{
17 Trata-se da velha máxima liberal de que o apoio ao trabalhador, através do fundo público, acomoda-o nesta condição e deve durar pouco tempo, estando aquém das menores remunerações normatizadas.

${ }^{18}$ Quando os CRAS possuem infra-estrutura física melhor, com espaço físico adequado e mais recursos financeiros, costumam ser oferecidos cursos na área da culinária básica.
} 


\section{frrabahonecessário}

\section{issn: $1808-799 x$}

ano 8 - número 11 - 2010

Partimos do princípio de que o PNQ como integrante do Plano Plurianual faz parte de um projeto de desenvolvimento que inclui a preparação de força de trabalho para as ocupações mais simples como um de seus eixos, da mesma forma, que a inserção produtiva dos CRAS. Estamos falando da organização de um projeto de formação de mãode-obra para áreas periféricas, desvinculado dos demais projetos de aprendizagem profissional (do Ensino Profissionalizante de Nível Médio e Superior, por exemplo), bem como da produção de Ciência e Tecnologia, distanciado ainda, da própria escola formal, o que nos dá evidências das limitações das propostas em curso.

Um país continental, com campos produtivos diversos e significativo número de jovens (para falarmos apenas de parte do público a que se destinam as qualificações), demanda verdadeiramente um projeto de formação que comporte, inclusive, aprendizagens dos níveis fundamentais. O modelo para tanto, porém, não pode estar limitado a aprendizagens simples e aligeiradas, frágeis na execução e na viabilização da permanência nos cursos, tal como tem ocorrido no PNQ e na proposta de inserção produtiva dos CRAS. Com perfil atual o que se efetiva e aprofunda é a perpetuação de um modelo produtivo organizado sobre a produção de bens simples e sobre o isolamento da produção científica em algumas poucas ilhas de excelência, gerando um plano de formação não abrangente, fragilíssimo de conteúdos, que aceita e aprofunda a condição de periferia produtiva do país na divisão internacional do trabalho.

As expectativas da sociedade brasileira frente à eleição de um governo com trajetória de esquerda não tem se confirmado e a dicotomia entre o que é afirmado e o que é efetivamente realizado, é gritante, em especial no campo ora analisado. Apesar de falar de educação integral e de direitos dos trabalhadores, constatamos no PNQ a transferência de recursos públicos para o sistema "S" e as ONGs, assim como verificamos a manutenção de formações rápidas, ajustadas somente pelas demandas de mercado e desenvolvidas marginalmente ao sistema escolar oficial. A perpetuação do padrão de gestão de FHC, portanto, fica evidente e ainda mais precarizado em se tratando de recursos, como pudemos ver. 


\section{frabahonecessário}

issn: 1808 - 799x

ano 8 - número 11 - 2010

A inserção produtiva dos CRAS, por sua vez, considerando o perfil de improviso em que esta se realiza, a despeito do esforço das equipes de profissionais que ali atuam, reedita a histórica prescrição compulsória do trabalho - leia-se qualquer trabalho — para os pobres, graças à interpretação liberal de que a assistência acomoda e desqualifica o exercício produtivo - ainda que os usuários da assistência, segundo o próprio MDS (2007), sejam trabalhadores do mercado informal. Neste sentido, é preciso reafirmar que a formação do PNQ se mostra frágil, mas a aprendizagem concretizada nos CRAS por sua precária infra-estrutura revela-se ainda mais empobrecida.

Observando ambas as experiências, verificamos estar diante de uma formação periférica no Plano, que corporifica a dualidade estrutural presente na educação brasileira e que estabelece no interior desta, uma nova dualidade, a da inserção produtiva dos CRAS. Em outras palavras, a inserção produtiva dos CRAS oferece aprendizado ainda mais precário do que aquele praticado no $P N Q$, revelando um aprendizado periférico, nas margens de outro aprendizado periférico.

Finalizando a presente reflexão, registramos que a qualificação de trabalhadores se adeqüa ao projeto de desenvolvimento nacional em curso - aqui entendido como neoliberal dotado de discurso social, ou desenvolvimentista subordinado e empobrecido. Através do PNQ e da inserção produtiva dos CRAS, têm sido preparada força de trabalho periférica, que realizará atividades simples e desprotegidas no mercado informal. Estes trabalhadores informais representam quase a metade da PEA, segundo já sinalizado aqui e não podem ser desconsiderados por um projeto de desenvolvimento que se pretenda agregador e conciliador de demandas do capital e trabalho (e o atual governo atua neste sentido). Esta força de trabalho representa um subproletariado (ANTUNES, 2000) que não pode ter sua existência negada e que precisa se integrar aos processos produtivos, de circulação e de consumo, ainda que perifericamente. Neste sentido, é inegável que estes programas buscam valorizar a condição de consumidor e portador de conta bancária daquelas populações que estavam às margens destes processos. Trata-se, portanto, de conferir às mesmas, uma cidadania limitada ao consumo e ao CPF. 


\section{frrabahonecessário}

issn: 1808 - 799x

ano 8 - número $11-2010$

Esta abordagem é útil ao projeto de desenvolvimento em processo. É preciso tornálos mais produtivos e consumidores ativos, é preciso neutralizar resistências a esta ordem e educar os mais pobres para estes tempos de trabalho precário e frágil. Vale ressaltar, que em ambas as experiências, tanto no PNQ, quanto nos CRAS, a capacidade de inserção ao mercado de trabalho formal é mínima - no caso do PNQ, o estudo do acesso dos usuários ao mercado de trabalho é pouco aprofundado nos instrumentos de avaliação do Plano. Já no caso dos CRAS, a meta é a geração de renda, o que fica bastante limitado, considerando os objetos produzidos (produtos artesanais) e sua capacidade de comercialização. Isso posto, entendemos que a potencialidade de ambas as experiências é muito mais ideológica no sentido da individualização e da naturalização do desemprego, de apassivamento (aliado à noção de pertencimento) ainda maior de uma mão-de-obra de grande visibilidade quantitativa, mas de pouca participação na vida política. Este quadro evidencia os limites destas experiências, revelando o quanto estas ações sofisticam a aprendizagem simples realmente existente.

\section{BIBLIOGRAFIA:}

ANTUNES, Ricardo. Adeus ao trabalho ? Ensaio sobre as metamorfoses e a centralidade do mundo do trabalho, $3^{\mathrm{a}}$ ed., Cortez: campinas, SP, 1995.

BEHRING, Elaine Rossetti. Política social no capitalismo tardio. São Paulo, Cortez, 1998

BORGES, Altamiro e POCHMANN, Marcio. Era FHC: a regressão do trabalho. São Pulo, Anita Garibaldi, 2002

Brasil. IBGE, Instituto Brasileiro de Geografia e Estatística e ABONG, Associação Brasileira de ONGs. As Fundações Privadas e Associações sem Fins Lucrativos no Brasil, 2005. Disponível em http://www.ibge.gov.br/home/estatistica/economia/fasfil/2005/, acesso em 12/03/2009

Brasil.IBGE, Instituto Brasileiro de Geografia e Estatística. Pesquisa Economia Informal Urbana. Disponível em www.ibge.gov.br, acesso em 04/01/2008

Brasil. IBGE. Pesquisa Mensal de Emprego. Fevereiro de 2009. Disponível em http://www.ibge.gov.br/home/estatistica/indicadores/trabalhoerendimento/pme nova/pmeri 200902comentarios.pdf, acesso em 03/04/2009

Brasil.IBGE/PNAD Pesquisa Nacional por Amostra de Domicílios - Volume Brasil, 2007, disponível em 


\title{
ftrabahonecessário
}

\author{
issn: 1808 - 799x \\ ano 8 - número 11 - 2010
}

www.ibge.gov.br/home/estatistica/populacao/trabalhoerendimento/pnad2007/default.shtm, acesso em setembro/2008

Brasil. IBGE/PNAD 2007 Perfil da Educação de Jovens e Adultos e da Educação profissional no Brasil. Disponível em

http://www.ibge.gov.br/home/presidencia/noticias/noticia visualiza.php?id noticia=1375\&id pagina=1, acesso em 22/05/2009

Brasil. IPEA. Mapa do Emprego. CAMPOS, Andre e AMORIM, Ricardo. Demanda e perfil dos trabalhadores formais no Brasil em 2007. Disponível em

http://www.ipea.gov.br/sites/000/2/destaque/mapadoemprego.pdf, acesso em 02/05/2009

Brasil.IPEA/Secretaria Especial de Políticas para as Mulheres e UNIFEM. Pesquisa

Retratos da desigualdade de gênero e raça. $3^{a}$ ed., Brasília, 2008. Disponível em

http://www.ipea.gov.br/sites/000/2/destaque/Pesquisa Retrato das Desigualdades.pdf, acesso em 04/04/2009

Brasil. DIEESE, CESIT. Emprego e desenvolvimento tecnológico. Artigos do

Pesquisadores nos Seminários Internacional e Regionais "Emprego e Desenvolvimento

Tecnológico". São Paulo, 1999

Brasil. DIEESE. Departamento Intersindical de Estatística e Estudos Sócio-econômicos Anuário dos Trabalhadores, 2005 Disponível em

http://www.mte.gov.br/pnq/anuario 2005.pdf, acesso em 12/03/2008

Brasil. DIEESE. Departamento Intersindical de Estatística e Estudos Sócio-econômicos Anuário da Qualificação Social e Profissional, 2006 Disponível em http://www.dieese.org.br/anu/Anuario qualificacao profissional.pdf

Brasil. DIEESE. Departamento Intersindical de Estatística e Estudos Sócio-econômicos Anuário da Qualificação Social e Profissional Anuário da Qualificação Social e Profissional, 2007 Disponível em www.mte.gov.br

Brasil. DIEESE. Departamento Intersindical de Estatística e Estudos Sócio-econômicos Anuário da Qualificação Social e Profissional Anuário dos Trabalhadores, 2008 Disponível em www.mte.gov.br

Brasil. DIEESE. CAGED (Cadastro Geral de Empregados e Desempregados), março de 2009. Disponivel em http://www.cntm.org.br/materias/imagens/\%7B25E3DE03-9AF049A4-8DB7-B2BB9D2EE3A8\%7D empregomar\%C3\%A7o.pdf.pdf., acesso em $07 / 05 / 2009$

Brasil. LEl 8352, de 28/12/1991, que dispõe sobre as disponibilidades financeiras do FAT

Brasil Lei 11692/2008, que dispõe sobre o Programa Nacional de Inclusão de Jovens, Projovem. Disponível em http://www.planalto.gov.br/ccivil 03/ Ato20072010/2008/Lei/L11692.htm, acesso em 24/02/2009

Brasil. LDB, Lei 9394/96 Lei de Diretrizes e Bases da Educação, disponível em http://portal.mec.gov.br/arquivos/pdf/ldb.pdf, acesso em 31/03/2006 


\title{
frrabahonecessário
}

\author{
issn: $1808-799 x$ \\ ano 8 - número 11 - 2010
}

Brasil. LOAS, Lei 8742/93. Lei Orgânica da Assistência Social, disponível em http://www.rio.ri.gov.br/smas/loas.pdf, acesso em 12/03/2008

Brasil. Ministério da Fazenda. PAC. Programa de Aceleração do Crescimento. Disponível em http://www.fazenda.gov.br/portugues/releases/2007/r220107-PAC.pdf, acesso em $12 / 02 / 2009$

Brasil. http://www.mds.gov.br/sites/conferencias-1/publicacoes-

1/publicacoes/?searchterm=Financiamento\%20da\%20assist $\%$ C3\%AAncia\%20social, acesso em 01/09/2008

Brasil. Ministério do Desenvolvimento Social e Combate à Fome, MDS. Promoção da Inclusão Produtiva (MDS, 2007). Disponível em http://www.mds.gov.br/sites/qualificacaode-instituicoes-para-participacao-em-processo-seletivo-para-implementacao-de-projetosde-inclusao-produtiva/inclusao-produtiva/?searchterm=inclus $\% \mathrm{C} 3 \% \mathrm{~A} 30 \% 20$ produtiva, acesso em 01/07/2008

Brasil. Ministério do Desenvolvimento Social e Combate à Fome. MDS. CRAS, institucional. Disponível em http://www.mds.gov.br/servicos/fale-conosco/assistenciasocial/gestor-tecnico-municipal/psb-2013-protecao-social-basica/cras-2013institucional/?searchterm=Programas $\% 20$ desenvolvidos $\% 20$ nos $\% 20$ CRAS, acesso em 01/07/2009

Brasil. Ministério do Desenvolvimento Social e Combate à Fome. MDS. MDS em números/Sudeste/Rio de Janeiro. Disponível em http://www.mds.gov.br/sites/mds-emnumeros/paginas/regioes/sites/mds-em-numeros/paginas/estados/rio-de-janeiro, acesso em 23/04/2009

Brasil. Ministério do Desenvolvimento Social e Combate à Fome. Jornal MDS, $\mathrm{n}^{0} 12$, fevereiro. Assessoria de Comunicação Social, Brasília, 2009

Brasil. Ministério do Desenvolvimento Social e Combate à Fome. Jornal MDS, $n^{0} 13$, fevereiro. Assessoria de Comunicação Social, Brasília, 2009

Brasil. Ministério do Trabalho e Emprego. MTE Sistema Público de Emprego e Educação Profissional. Implementação de uma política integrada. Brasília, 1996

Brasil. Ministério do Trabalho e Emprego. MTE Indicadores de Mobilidade Ocupacional. Dados do Sistema SINE, 2008. Disponível em http://www.mte.gov.br/sine/relatorio anual2008.pdf, acesso em 12/04/2009

Brasil. PLANFOR. Plano Nacional de Formação Profissional. MTE. Termo de referência de Projetos Especiais, 1996a

Brasil. Plano Nacional de Qualificação, PNQ, 2003/2007 MTE. Disponível em www.sine.pr.gov.br/setp/cqp/Pnq_2003_07.pdf , acesso em 02/07/2006

BRAZ, Marcelo. O PAC e o serviço social: crescimento para quê e para quem? Os setenta anos da profissão e seus desafios conjunturais. In. Revista Serviço Social e Sociedade, Ano XXVIII, n 91, São Paulo, Cortez, 2007 


\title{
frrabahonecessário
}

\author{
issn: $1808-799 x$ \\ ano 8 - número 11 - 2010
}

CAMPOS, Maria Malta. Educação e políticas de combate à pobreza Revista Brasileira de Educação, n² 243, set/out/nov/dez, 2003

CEA, Georgia Sobreira dos Santos. A qualificação profissional como instrumento de regulação social. $27^{\mathrm{a}}$ Reunião da ANPED, 2004. Em disponível em http://www.anped.org.br/reunioes/27/gt09/t099.pdf, acesso em 07/03/2009

PLANFOR, reforma do Estado e acumulação

flexível: tecendo fios invisíveis. Educere et Educare Revista de Educação. Vol I, $\mathrm{n}^{\circ} 2$, jul;/dez. 2006, p. 229/244, disponível em e-

revista.unioeste.br/index.php/educererevistaeducacao/article/vewfile/206/195, acesso em $12 / 05 / 2008$

Censo Escolar 2005. MEC, INEP, disponível em www.inep.gov.br/basica/censo, acesso em 22/03/2008

CNI. Confederação Nacional da Indústria. Educação para a nova indústria. Uma ação para o desenvolvimento sustentável. Proposta de ação do Sistema Indústria, em consonância com as diretrizes do mapa estratégico da indústria. CNI, SESI, SENAI, agosto, 2007 Disponível em

http://www.cni.org.br/portal/data/pages/8A9015D218CCF2730118CD1BA3180A08.htm, acesso em 21/01/2009

COUTINHO, Carlos Nelson. O Estado brasileiro: gênese, crise, alternativas, In, LIMA, Júlio César França e NEVES, Lucia Maria Wanderley. Fundamentos da educação escolar no Brasil contemporâneo. Rio de Janeiro, Editora Fiocruz, 2006

CUNHA, Luis Antonio. Educação, Estado e Democracia no Brasil, $2^{a}$ ed, São Paulo, Editora Cortez,; Niterói, RJ, Editora Universidade Federal Fluminense, 1995

O ensino de ofícios nos primórdios da industrialização. São Paulo:

UNESP, $2000(a)$

UNESP, 2000 (b)

O ensino profissional na irradiação do industrialismo. São Paulo:

DEDECCA, Claudio Salvadori, BARBOSA, Alexandre Freitas e MORETTO, Amilton. Transformações recentes de empregos nos países desenvolvidos: tendências e particularidades. In OLIVEIRA, Roberto Veras de. Novo momento para as comissões de emprego no Brasil ? Sobre as condições da participação e controle sociais no sistema público de emprego em construção. SãoPaulo, A+ Comunicação e Unitrabalho, 2007

FIDALGO, Fernando, e FIDALGO, Nara Luciene Rocha. Refluxos sociais da lógica das competências: o processo de individualização em foco. IN, FIDALGO, Fernado, OLIVEIRA, Maria Auxliadora Monteiro e FIDALGO, Nara Luciene. (org). Educação Profissional e a lógica das competências: Petrópolis/RJ, Vozes, 2007

FRIGOTTO, Gaudêncio.. Educação e crise do trabalho assalariado e do desenvolvimento: teorias em conflito. In FRIGOTTO, Gaudêncio (org) Educação e crise do trabalho.

Perspectivas de final de século. Petrópolis, RJ: Vozes, 1998 


\author{
issn: $1808-799 x$ \\ ano 8 - número 11 - 2010
}

Guia PlanTeQ/2008. Secretaria de Estado de Trabalho e Renda. SETRAB/RJ Disponível em http://www.trabalho.ri.gov.br/download/PLANTEQ2008.pdf, acesso em 12/12/2008

GONÇALVES, Reinaldo. Crise econômica: radiografia e soluções para o Brasil, ... ano 2008

GRAMSCI, Antonio. Os intelectuais e a organização da cultura. $6^{\circ}$ ed. Rio de Janeiro, Civilização Brasileira, 1988

HOBSBAWN, Eric. O novo século. Entrevista a Antonio Polito: São Paulo, Cia das Letras, 2009

IBASE. Repercussões do PBF na segurança alimentar e nutricional das famílias beneficiadas. Disponível em http://www.ibase.brl, acesso em 12/06/2008

KRÜGER, Valdelucia Amaral. As determinações restritivas das políticas públicas de qualificação profissional e os limites do PNQ. UFPR, disponível em www.ppgte.cefetpr.br/dissertacoes/2006/valdelucia/pdf, acesso em 22/11/2007

KUENZER, Acacia. A exclusão includente e a inclusão excludente: a nova forma de dualidade estrutural que objetiva as novas relações entre educação e trabalho. Semana pedagógica Paraná. Disponível em

http://www.diaadia.pr.gov.br/det/arquivos/File/SEMANAPEDAGOGICA/13 ExclusaoIncludente-Acacia Kuenzer.pdf, acesso em 08/05/2009

A Educação profissional nos anos 2000. A dimensão subordinada das políticas de inclusão. Campinas, SP. Revista Educação e Sociedade, vol 27, n 96, out 2006. Disponível em http://www.scielo.br/pdf/es/v27n96/a12v2796.pdf, acesso em 12/03/2009

MANFREDI, Silvia Maria. Educação Profissional no Brasil. São Paulo, Cortez, 2003

MARX, Karl. O capital. Crítica da economia política. O processo de produção de capital. São Paulo: Nova Cultural, 1985

MÉSZÁROS, István. Desemprego e precarização: um grande desafio para a esquerda. In, ANTUNES, Ricardo (org). Riqueza e miséria do trabalho no Brasil. São Paulo: Boitempo Editorial, 2006

NETTO, José Paulo. Marxismo impenitente. Contribuição à história das idéias marxistas. São Paulo: Cortez, 2004

NEVES, Lúcia Maria Wanderley e SANT'ANNA, Ronaldo. Introdução: gramsci, o Estado educador e a nova pedagogia da hegemonia. In NEVES, Lúcia Maria Wanderley. A nova pedagogia da hegemonia. Estratégias do capital para educar o consenso. São Paulo, Xamã, 2005

Observatório Jovem. IBGE divulga perfil da EJA e da Educação profissional no país. Disponível em http://www.observatoriojovem.org/materia/ibge-divulga-perfil-da-eja-e-daeduca\%C3\%A7\%C3\%A3o-profissional-no-pa\%C3\%ADs, acesso em junho 2009 


\section{frabahonecessário}

issn: $1808-799 x$

ano 8 - número 11 - 2010

OLIVEIRA, Ramon. Agências Multilaterais e a Educação Profissional Brasileira. Campinas, SP: Alínea, 2006

PNUD. Programa das Nações Unidas para o Desenvolvimento. Programa de Objetivos do Milênio. Disponível em

http://www.ipea.gov.br/sites/000/2/download/TerceiroRelatorioNacionalODM.pdf, acesso em 02/04/2009

POCHMANN, Marcio. Inserção Ocupacional e o emprego dos jovens. São Paulo: ABET, 1998

SAVIANI, Demerval. O trabalho como princípio educativo frente às novas tecnologias. IN, FERRETTI, Celso João, ZIBAS, Dagmar, MADEIRA, felícia e FRANCO, Maria Laura (org).Novas tecnologias de trabalho e educação. Um debate multidisciplinar. Petrópolis, RJ, Vozes, 1994

RUMMET, Sonia Maria.Educação e Identidade de trabalhadores. As concepções do capital e do trabalho. Niterói/RJ, Xamã, 2000

SAUL, Ana Maria, FREITAS, José Cleber de, KOYAMA, Sérgio Mikio e LUNA, Sergio Vasconcelos de. Pesquisa com egressos das ações dos Plan TeQs. In SAUL, Ana Maria e FREITAS, José Cleber de (Orgs) Políticas Públicas de Qualificação. São Paulo, A+ Unitrabalho, 2007

SAUL, Ana Maria, FREITAS, José Cleber de, KOYAMA, Sérgio Mikio e LUNA, Sergio Vasconcelos de. Síntese avaliativa dos Planos Territoriais de qualificação - PlanTeQs 2003-2005. In SAUL, Ana Maria e FREITAS, José Cleber de (Orgs) Políticas Públicas de Qualificação. São Paulo, A+Unitrabalho, 2007b

SENNETT, Richard. A corrosão do caráter. Conseqüências pessoais do trabalho no novo capitalismo. São Paulo: Record, 2004

TOFFLER, A. A terceira onda: Rio de Janeiro, Record, 1980 